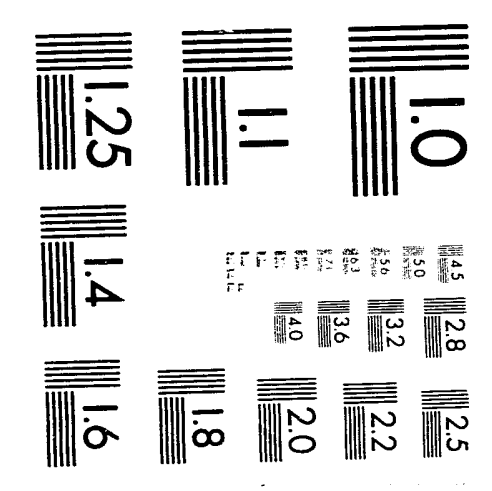



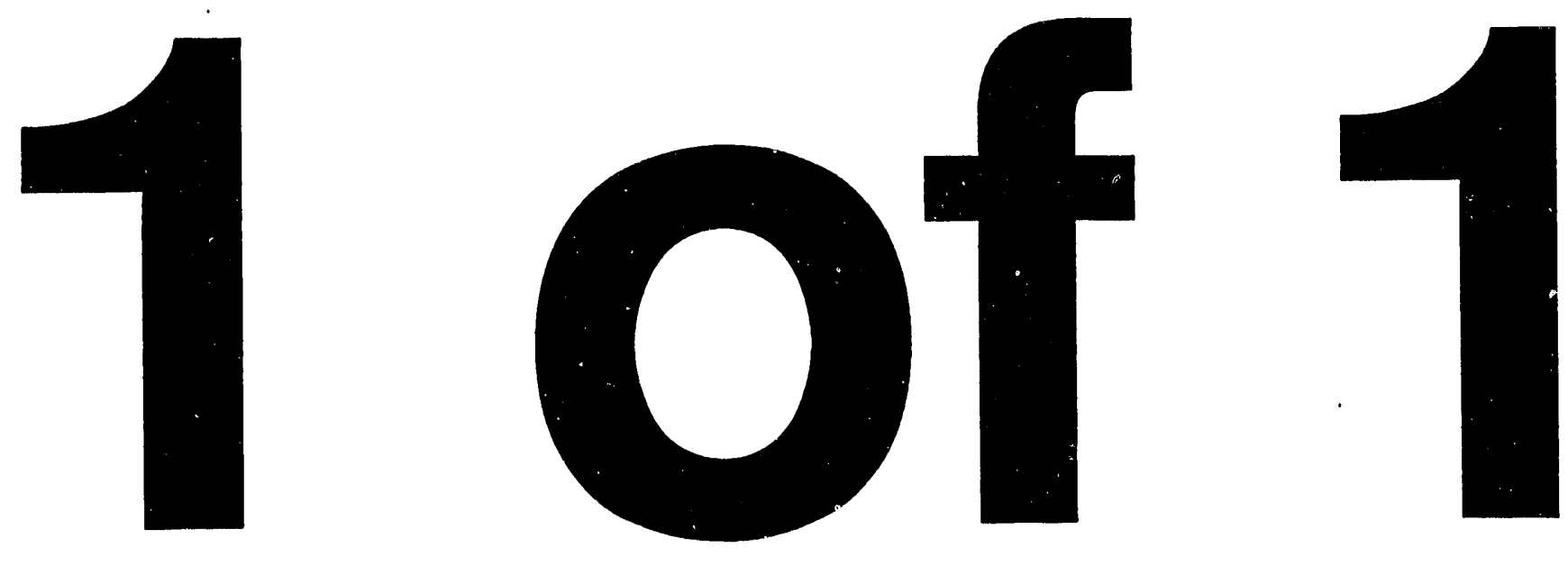


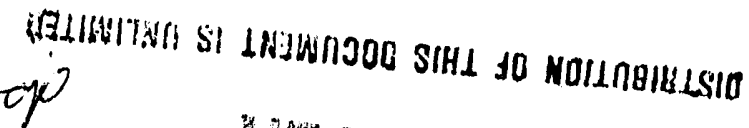

\section{Dering}

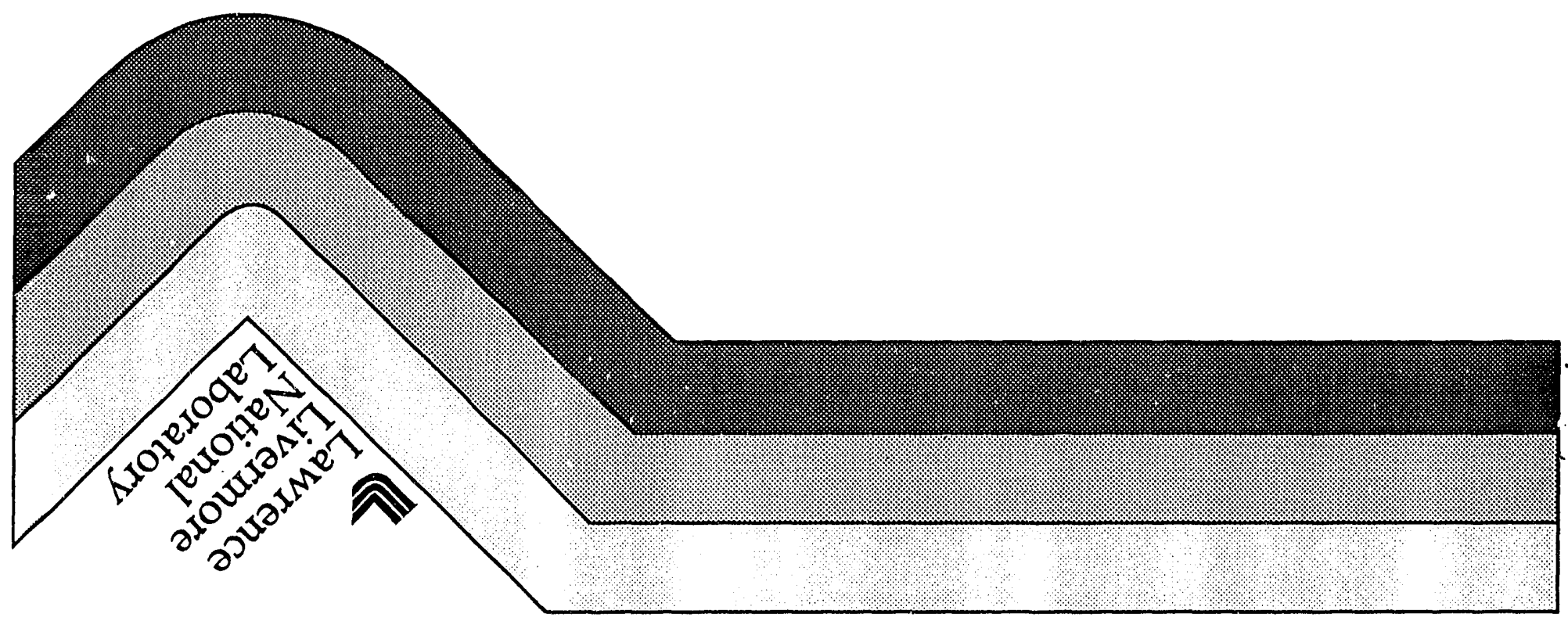

E66I'tz aunf

yдомspe $M$ 'f

Yว!N ${ }^{\circ} \mathbf{L}$

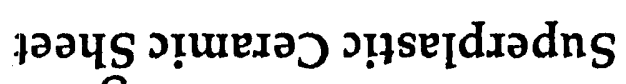

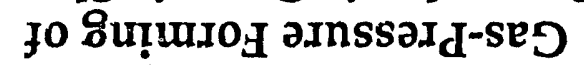




\section{DISCLAIMER}

Work performed under the auspices of the U.S. Department of Energy by Lawrence Livermore National Laboratory under contract number W-7405-ENG-48.

This document was prepared as an account of work sponsored by an agency of the United States Government. Neither the United States Government nor the University of California nor any of their employees, makes any warranty, express or implied, or assumes any legal liability or responsibility for the accuracy, completeness, or usefulness of any information, apparatus, product, or process disclosed, or represents that its use would not infringe privately owned rights. Reference herein to any specific commercial products, process, or service by trade name, trademark, manufacturer, or otherwise, does not necessarily constitute or imply its endorsement, recommendation, or favoring by the United States Government or the University of California. The views and opinions of authors expressed herein do not necessarily state or reflect those of the United States Government or the University of California, and shall not be used for advertising or product endorsement purposes. 


\title{
Gas-Pressure Forming of Superplastic Ceramic Sheet
}

\author{
T.G. Nich and J. Wadsworth
}

\author{
Lawrence Livermore National Laboratory, L-350, P.O. Box 808, Livermore, CA 94551, USA
}

Superplasticity in ceramics has now advanced to the stage that technologically viable superplastic deformation processing can be performed. In this paper, examples of biaxial gas-pressure forming of several ceramics are given. These include yttria-stabilized, tetragonal zirconia (YTZP), a 20\% alumina/YTZP composite, and silicon. In addition, the concurrent superplastic forming and diffusion bonding of a hybrid YTZP/C103 (ceramic-mctal) structure are presented. These forming processes offer technological advantages of greater dimensional control and increased variety and complexity of shapes than is possible with conventional ceramic shaping technology.

\section{BACKGROUND}

The forming of ceramics is generally difficult because the melting points of ceramics are relatively high and, consequently, the temperatures required to plastically deform ceramics are also high. The propensity for grain boundary separation in ceramics is also well-known. In the 1950s, extensive efforts were made in the western world and the former Soviet Union to hot fabricate ceramics using conventional metallurgical processes such as extrusion, rolling, and forging [1]. The goal was to produce near-net-shape parts in order to avoid expensive machining. A number of structural oxides, including $\mathrm{CaO}, \mathrm{MgO}, \mathrm{SiO}_{2}$, $\mathrm{ZrO} 2, \mathrm{BeO}, \mathrm{ThO}_{2}$, and $\mathrm{Al}_{2} \mathrm{O}_{3}$, was studied. As a result of this work, an improved understanding of ceramic deformation was developed but certain problems, and in particular the requirement for relatively high forming temperatures, still existed. For example, the temperature required for hot forging $\mathrm{Al}_{2} \mathrm{O}_{3}$ was found to be approximately $1900^{\circ} \mathrm{C}$, which is extremely high from a practical standpoint. Subsequently, the concept of thermomechanical processing of ceramics was more-or-less abandoned.

Recent technical advances have changed this picture. First, advances in ceramic powder processing technology has greatly improved the quality of ceramic powders. High-purity ceramics of submicron very grain size and more consistent microstructures are routinely prepared. Secondly, the observation that very fine-structure ceramic materials can exhibit superplastic behavior has led to an intensive study of fundamental issues affecting the deformation behavior of ceramic materials. As a result, the science of ceramic superplasticity is now well-advanced with issues such as grain size effects [2], the role of grain boundary impurity [3], cavitation [4], concurrent grain growth [5], and elevated-temperature flow characteristics [6,7] well-documented for a number of ceramic systems.
Improved understanding of these fundamental issues has advanced to the stage that technological application of ceramic superplastic deformation is receiving increasing attention. Examples include the extrusion of YTZP powders [8], closed die deformation of YTZP [9], punch forming of YTZP sheet [10] and, most recently, biaxial gas-pressure deformation of $20 \% \mathrm{Al}_{2} \mathrm{O}_{3} / Y$ TZ'P [11], YTZP [12], and $\mathrm{Fe} / \mathrm{Fe}_{3} \mathrm{C}$ [13]. This paper presents examples of the superplastic forming of several ceramics via biaxial gas-pressure forming techniques, including YTZP, $20 \% \mathrm{Al}_{2} \mathrm{O}_{3} / \mathrm{YTZP}$, and silicon. In addition, we will present an example' of the concurrent superplastic forming and diffusion bonding (SPF/DB) of a hybrid ceramic-metal (YTZP/C103) structure.

\section{EXPERIMENTS}

The equipment used to perform gas-pressure deformation has bben described elsewhere [12]. The key features are shown in Fig. 1 . For all experiments, high-purity argon gas was used to impose the deformation pressure. In-situ deformation is measured when the diaphragm expands upwards to form a hemisphere; this displaces a silicon carbide sensor rod linked to an LVDT. The forming pressure was monitored both with a dial indicator as well as with an electronic DC strain gauge pressure transducer. The apparatus was inductively heated and fully enclosed within a vacuum chamber. A typical heat-up time was 30 minutes with a ten minute hold time prior to the application of forming pressure. All experiments were conducted isothermally under conditions of constant applied forming pressure and an ambient of $25 \mathrm{kPa}$ argon. Materials for this study were in the form of $50 \mathrm{~mm}$ diameter discs, $1.5 \mathrm{~mm}$ in thickness. The discs were clamped at their periphery resulting in an unconstrained diaphragm with a diameter of $38 \mathrm{~mm}$, producing a hemisphere of $19 \mathrm{~mm}$ in height. 


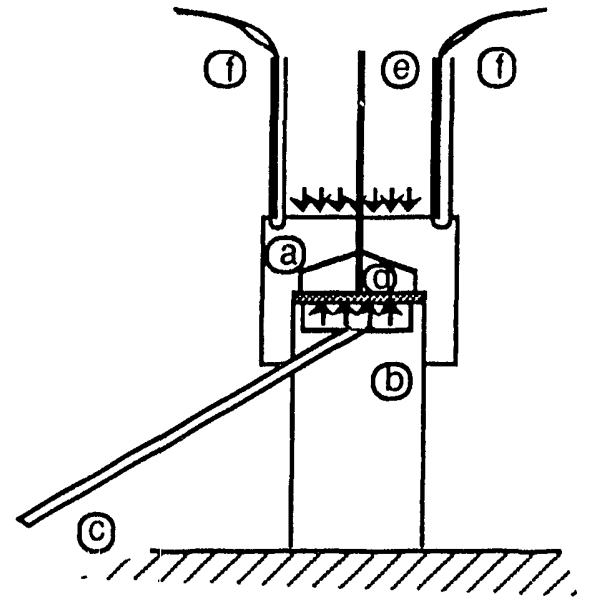

Fig. 1 Gas-pressure forming apparatus. Upper die (a) and lower die (b). Gas is admitted through integral pressure tube (c), ceramic diaphragm (d) deforms upwards causing movement of deflection sensor (e). T'emperature is monitored by twin thermocouples $(f)$.

\section{RESULTS}

\subsection{Yttria-Stabilized, Tetragonal Zirconia}

Polycrystal (YTZP)

Forming experiments were conducted over a temperature range of $1450^{\circ}$ to $1600^{\circ} \mathrm{C}$ and forming pressures in the range of 345 to $2760 \mathrm{kPa}$. These forming temperatures and pressures were chosen to impart true strain rates over the range of , approximately $10^{-5}$ to $10^{-2} \mathrm{~s}^{-1}$.

The forming behavior for YTZP sheet at a pressure of $690 \mathrm{kPa}$ at various temperatures is summarized in the deformation-time plots of Fig. 2. Data in Fig. 2 exhibit three distinct regions of behavior as deformation progresses for each of the experimental conditions examined. Initially, the height of the deforming dome increases quite rapidly. This stage is followed by a period of apparent steady-state deformation. Finally, as the height approaches that of a hemisphere, the deformation rate increases again. The three-stage behavior shown in Fig. 3 appears to be similar to the creep curve of metal alloys deformed under a constant value of uniaxial stress. In the present case, however, the interpretation is quite different. Although the applied forming pressure remains constant throughout the test, the resultant stress acting in the deforming shell varies continuously during the course of deformation. As the thickness and radius of a deforming shell are interdependent, the second stage of deformation occurs at an approximately constant rate because the decreasing radius of curvature is balanced by the decreasing shell thickness. In fact, the three-stage behavior observed in Figure 2 not only results from the creep of the material but also from the nature of constantpressure biaxial forming [12].

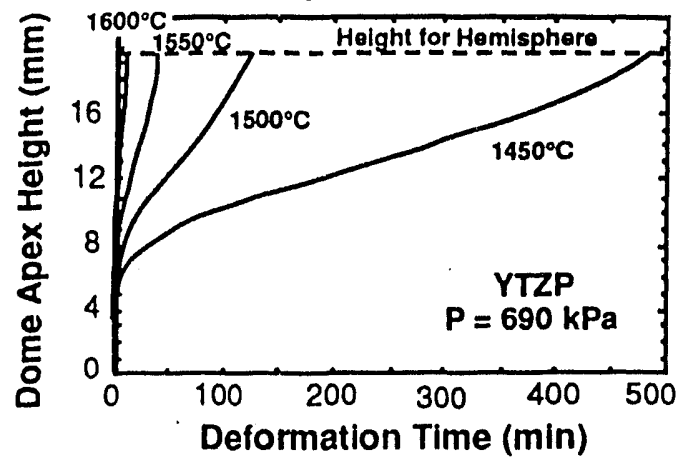

Fig. 2 Deformation-time curves for superplastic gas-pressure forming of YTZP.

For the testing conditions employed in this investigation, the relationship between flow stress and dome apex height has been calculated and is shown in Fig. 3. For discussion purposes, a nominal flow stress was selected through numerical integration of the curves shown in Fig. 3 - using a height of $5 \mathrm{~mm}$ as the lower limit of integration. Note in Fig. 3 that for each forming pressure used, the predicted shell stress is closely approximated by a single nominal flow stress for a large portion of the test. This corresponds to the "steady-state" deformation (region 2) observed in the deformationtime plots presented in Fig. 2. The calculated results presented in Fig. 4 show that the imposed flow stress levels for the experiments of this study spanned the range of $3.75 \mathrm{MPa}$ to $30 \mathrm{MPa}$. For each hemisphere formed, an average strain rate was calculated by simply dividing the final true apex thickness strain by the duration of the test. (It is clear that the strain rate changes continuously during the forming experiment for the constant forming pressure condition. The determination of average strain rate, therefore, provides only a first-order result.) In this manner, the forming stress-strain rate data are presented graphically as a $\log -\log$ plot in Fig. 4. The data indicate that, at all temperatures, the average strain rate $\dot{\varepsilon}$, is proportional to the nomina! flow stress raised to the $n$th power, i.e.:

$$
\dot{\varepsilon}=B \cdot \sigma^{n}
$$

The data of Fig. 5 exhibit a stress exponent $n$ of 2 for the tests conducted at high applied pressure with $n$ increasing to a value of 3 at lower applied stresses. A stress exponent of 3 in the low stress (or low strain rate) region is in agreement with results previously obtained from uniaxial tension tests (without compensating for dynamic grain growth during deformation). An increasing stress exponent in the low stress region has been observed 
previously in superplastic YTZP and was attributed to dynamic grain growth.

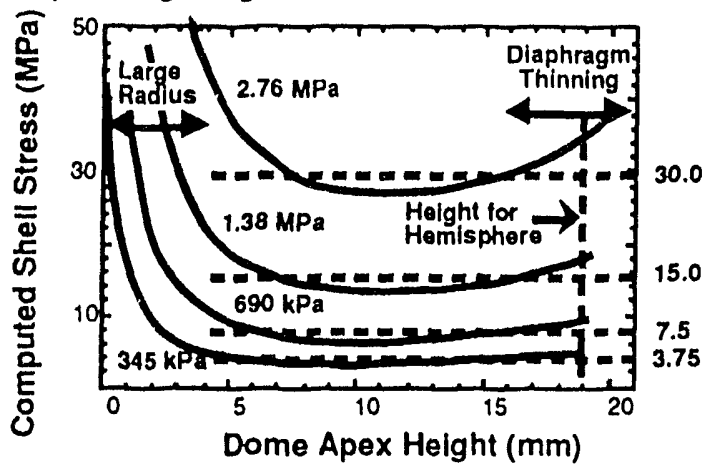

Fig. 3 The relationship between shell stress and dome apex height.

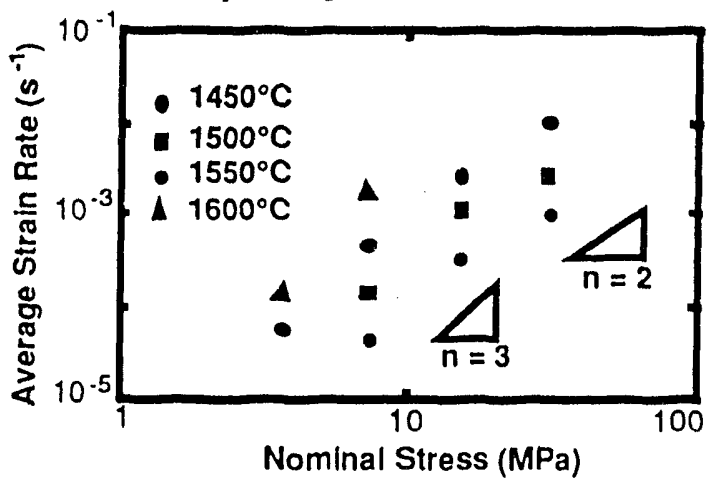

Fig. 4 Average strain rate versus nominal stress.

A direct comparison between the strain ratestress data obtained from the present biaxial forming experiments and those from uniaxial testsis shown in Fig. 5. It is particularly pointed out that the nominal shell stress for the biaxial tests used in Fig. 4 is, in fact, a tangential stress. For the case of biaxial forming, both a tangential and an equal circumferential stress act at the dome apex (the thickness stress is zero). The effective stress, as used in Fig. 4, acting on the dome apex is the resultant of these two stresses, which equals $\sqrt{2}$ times the stress value indicated in Fig. 4 . It is evident in Fig. 6 that, despite the fact that the strain rate from the biaxial forming test is generally faster than that from the uniaxial tests, both sets of data indicate a slightly decreasing stress exponent in the high strain rate region.

\subsection{Alumina/YTZP}

In the case of $\mathrm{Al}_{2} \mathrm{O}_{3} / \mathrm{YTZP}$, the hemispheres were deformed at temperatures between 1450 and $1600^{\circ} \mathrm{C}$, and at forming pressures of 345 and $690 \mathrm{kPa}$. For these forming pressures and temperatures, $20 \% \mathrm{Al}_{2} \mathrm{O}_{3} / \mathrm{YTZP}_{\mathrm{T}}$ discs could be readily deformed into hemispherical caps over times ranging from $10^{3}$ to $2 \times 10^{4} \mathrm{~s}$.

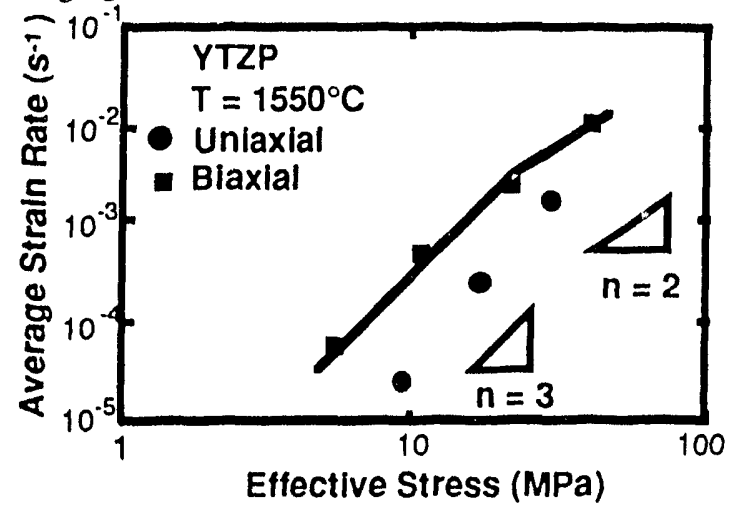

Fig. 5 A direct comparison between data from biaxial and uniaxial tests.

The biaxial forming behavior for $\mathrm{Al}_{2} \mathrm{O}_{3} / Y \mathrm{TZP}$ sheet is similar to that for YTZP. Namely, the forming curves essentially consist of three distinct regions. The experimental results indicate that the $n$ value is approximately in the range from 2 to $3 ; n$ is 3 at $1500^{\circ} \mathrm{C}$, but decreases to about 2 at $1550^{\circ} \mathrm{C}$. These $n$ values are in the usual range for superplastic ceramics. Again, data from the biaxial tests can be well correlated with that from the uniaxial tests. The strain rate from the biaxial forming test is about 3-4 times faster than that from the uniaxial tests; this result is similar to that found in YTZP.

\subsection{Silicon}

Silicon is difficult to deform because of its diamond structure (covalent). Although some reported hot hardness data indicated that Si softens at about $600-800^{\circ} \mathrm{C}$, the tensile ductility of $\mathrm{Si}$ becomes appreciabie only at temperatures above $1300^{\circ} \mathrm{C}$ (melting point of Si is $1414^{\circ} \mathrm{C}$ !) [14].

Net-shape forming of $\mathrm{Si}$ using casting techniques poses a major technical challenge because of strong chemical reactions between molten silicon and most crucible materials. In addition, $S i$ virtually reduces the melting points of any chemical constituent. However, by proper selection of the mold material, the release agent for the mold, and the applied gas pressure, we have successfully formed single-crystal Si wafers into dome shapes [15]. A Si dome formed at $1375^{\circ} \mathrm{C}$ is shown in Fig. 6. This dome is noted to exhibit a textured appearance, resulting from the constrained deformation of the single crystal.

\subsection{Hybrid YTZP/C103 (SPF/DB)}

A combination of superplastic deformation with diffusion bonding offers the opportunity to manufacture a range of useful enginecring structures. As an example of the potential for manufacturing metal-ceramic hybrids, the diffusion 
bonding and co-deformation of a YTZP ceramic disc and the Nb-based refractory alloy C-103 (nominal composition: $\mathrm{Nb}-10 \mathrm{Hf}-1 \mathrm{Ti}$.) has been evaluated [16]. Alloy $\mathrm{C}-103$ is a single-phase solid solution strengthened $\mathrm{Nb}$ alloy commonly used in spacecraft propulsion systems. Discs of YTZP and C-103 were assembled into the biaxial gas-pressure deformation apparatus and co-deformed at $1500^{\circ} \mathrm{C}$. The hybrid assembly was successfully made. Such a thinwalled engineered metal-ceramic structure could have great utility in high thermal flux applications.

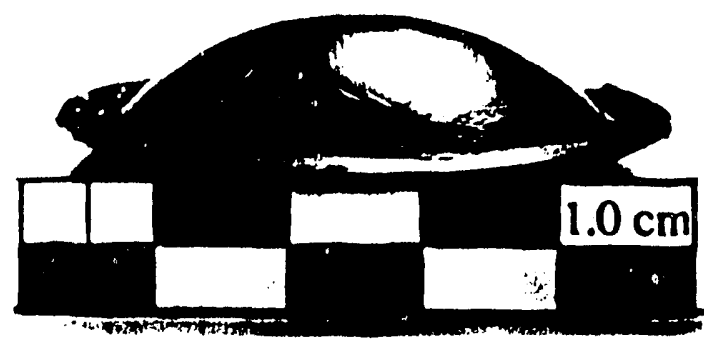

Fig. 6 A Si dome biaxial formed at $1375^{\circ} \mathrm{C}$.

\section{SUMMARY}

In the past decade, ceramic superplasticity has rapidly advanced from a period of fundamental laboratory study to a level at which ceramic articles may be formed superplastically by gas pressure deformation. Using the technology developed for the present study, it is now possible to make intricately shaped, net shaped parts from superplastic ceramic sheet. Examples of a cone-on-cylinder geometry, a hat section, and a hemisphere are shown in Fig. 7. Various shape geometries are possible with this process - as determined by the shape of the die. Continued studies are needed to understand the relationships between deformation variables (pressure, temperature) and deformation behavior (forming rate, strain distribution, cavitation).

\section{ACKNOWLEDGMENT}

The financial support by the Army Research Office under contract DAAL03-89-C-0028 is appreciated. The authors would like to thank Dr. J.P. Wittenauer for his technical contributions.

\section{REFERENCE}

1. R.W. Rice, in High Temperalure Oxides, Refractory Materials 5-111, ed. by A.M. Alper, New York, Academic Press, 1970, pp. 235-280.

2. T.G. Nieh and J. Wadsworth, Scripta Metall. Mater., 24, 763 (1990).
3. T.G. Nich, D.L. Yaney, and J. Wadsworth, Scripta Metall., 23, 2007 (1989).

4. D.J. Schissler, A.H. Chokshi, T.G. Nich, and J. Wadsworth, Acta Metall. Mater., 39, 3227 (1991).

5. A.H. Chokshi, T.G. Nich, and J. Wadsworth, J. Am. Ceram., Soc., 74, 869 (1991).

6. F. Wakai, S. Sakaguchi, and Y. Matsuno, $A d v$. Ceram. Mater., 1, 259 (1986).

7. F. Wakai, S. Sakaguchi, and H. Kato, J. Ceram Soc. Jap., 94, 72 (1986). (In Japanese)

8. B. Kellett, P. Carry, and A. Mocellin, in Superplasticity and Superplastic Forming, cdited by C.H. Hamilton and N.E. Paton, The Minerals, Metals, and Materials Society, Warrendale, PA, 1988 , pp. 625-630

9. F. Wakai, Brit. Ceram. Trans. , 88, 205 (1989).

10. X. Wu and I.W. Chen, J. Am. Ceram. Soc., 73, 746 (1990).

11. J.P. Wittenauer, T.G. Nieh, and J. Wadsworth, Scripta Metall. Maters., 26, 551 (1992).

12. J.P. Wittenauer, T.G. Nieh, and J. Wadsworth, J. Amer. Ceram. Soc., (1993). (in press).

13. O.D. Sherby, unpublished work (1993).

14. D.W.Lillie, Trans.TMS-AIME, p.249, April 1958.

15. Lockheed Independent Research Report, no. LMSC-F418432, pp. 4-185 to 4-193 (1992).

16. J.P. Wittenauer, T.G. Nieh, and J. Wadsworth, in Processing and Fabrication of Advanced Materials, ed. J.J. Morris, The Minerals, Metals \& Materials Society, Warrendalc, PA, (1993). (in press)

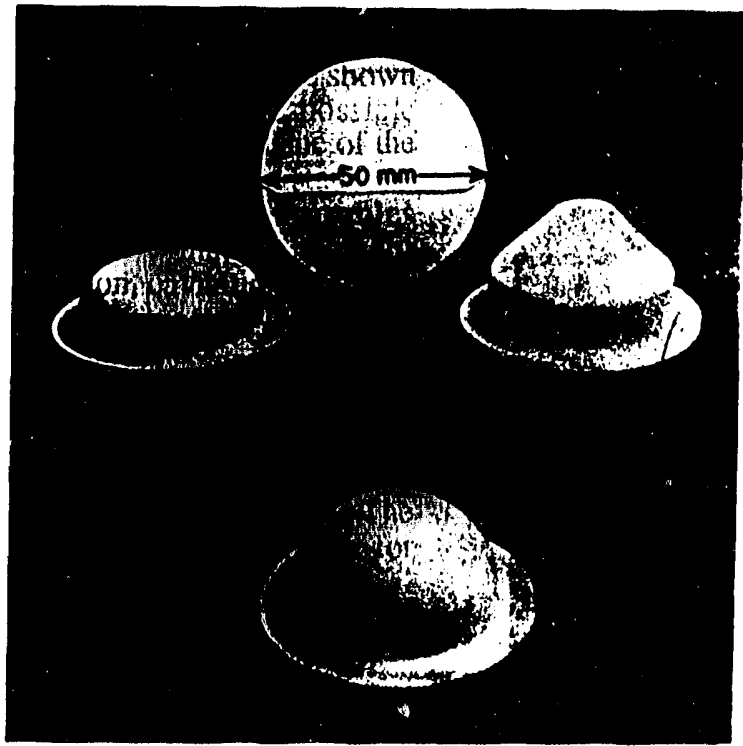

Fig. 7 Examples of a cone-on-cylinder geometry, a hat section, and a hemisphere. 

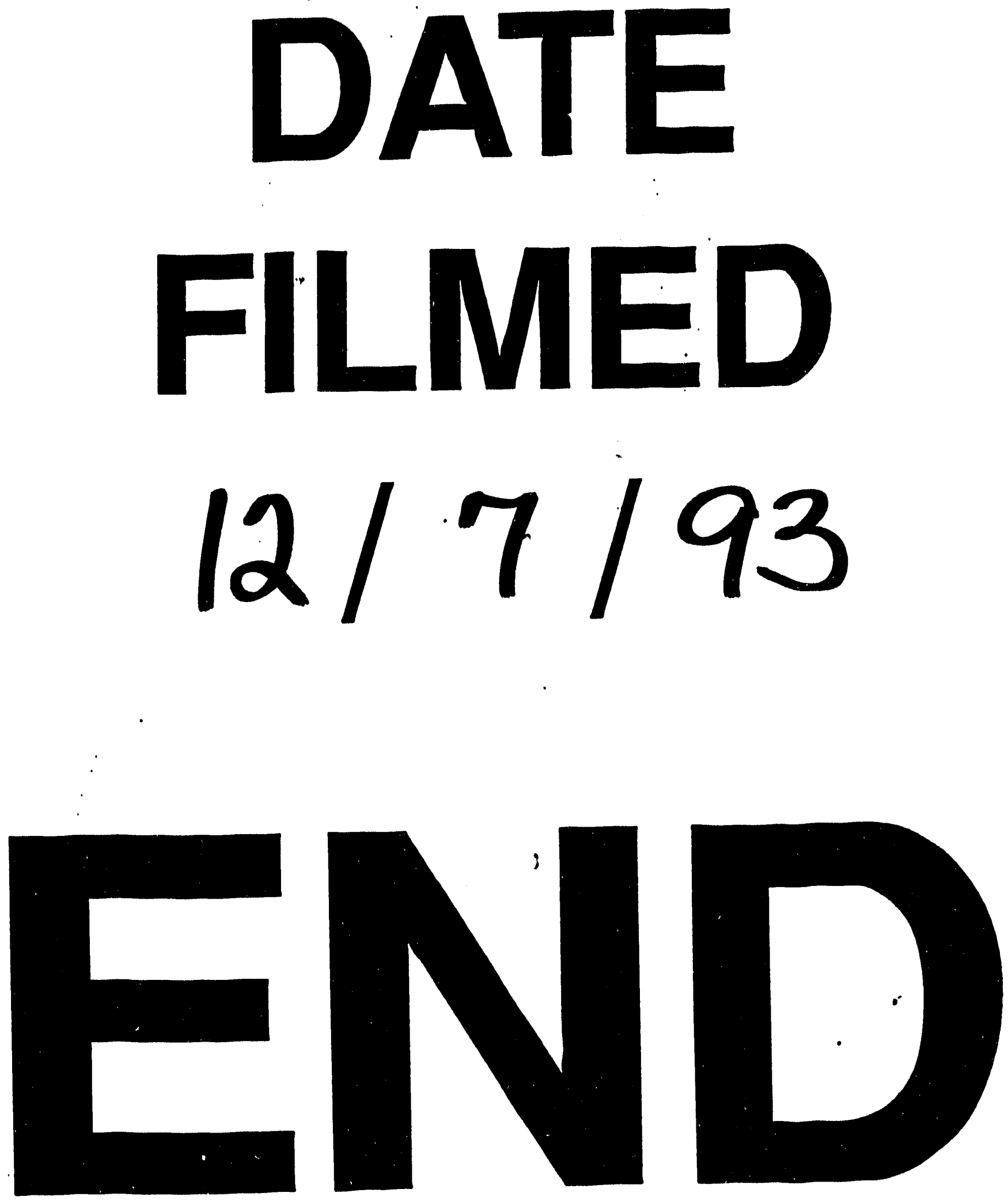
$$
\text { - - }
$$

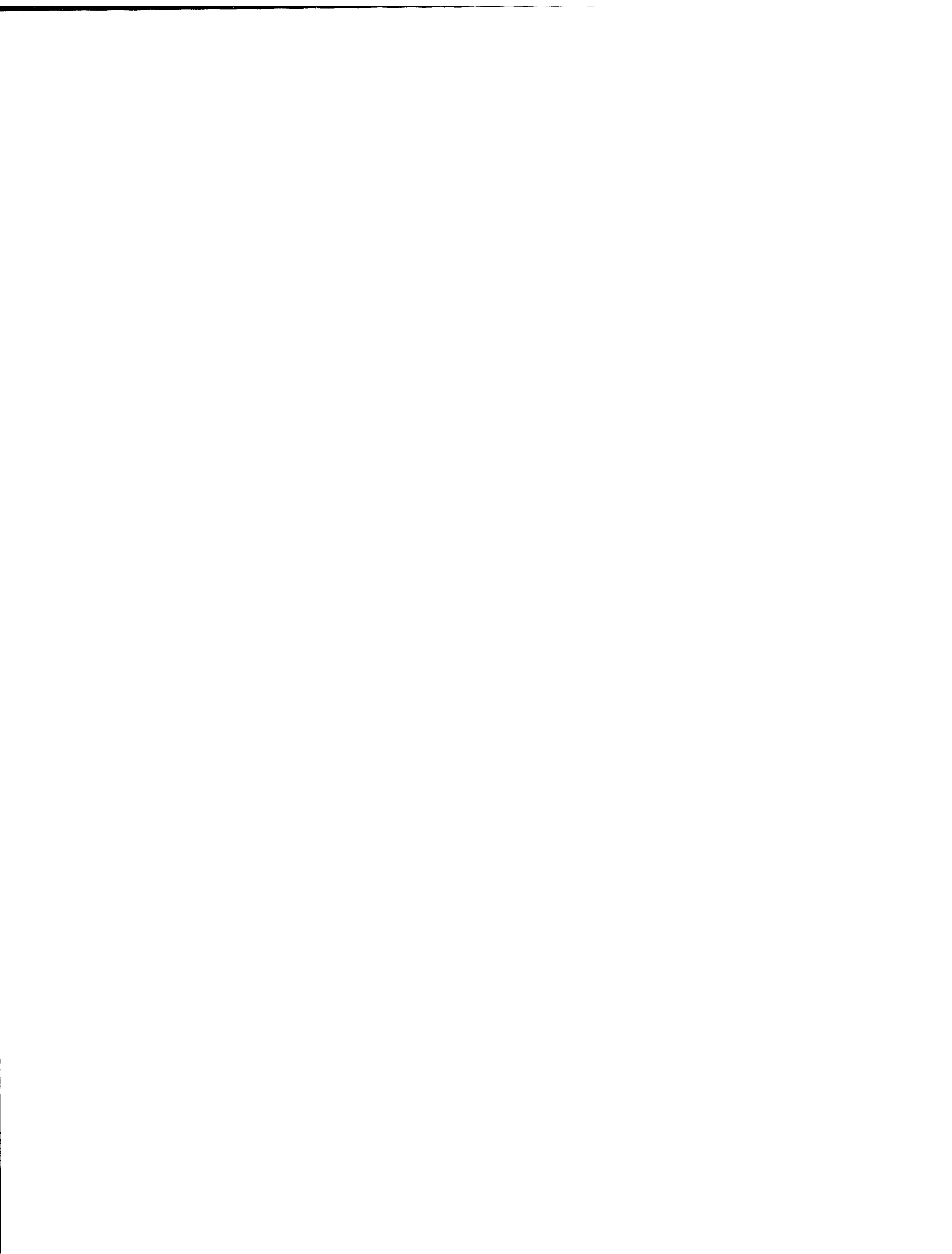

